\title{
Evaluation of blood pressure through home monitoring in brazilian primary care: a feasibility study
}

\author{
Avaliação da pressão arterial através da monitorização residencial \\ na atenção básica brasileira: um estudo de viabilidade
}

\author{
Jéssica Nunes Moreno (https://orcid.org/0000-0003-0741-9181) 1 \\ Welma Wildes Amorim (https://orcid.org/0000-0001-6964-892X ) 2 \\ Sóstenes Mistro (https://orcid.org/0000-0001-5840-820X ) ${ }^{1}$ \\ Danielle Souto de Medeiros (https://orcid.org/0000-0002-2480-8990) ${ }^{1}$ \\ Matheus Lopes Cortes (https://orcid.org/0000-0002-7804-7787) ${ }^{1}$ \\ Daniela Arruda Soares (https://orcid.org/0000-0002-4801-1011) ${ }^{1}$ \\ José Andrade Louzado (https://orcid.org/0000-0003-4446-7051) ${ }^{1}$ \\ Clavdia Nicolaevna Kochergin (https://orcid.org/0000-0002-3272-3030) ${ }^{1}$ \\ Kelle Oliveira Silva (https://orcid.org/0000-0003-2041-1088) ${ }^{1}$ \\ Vanessa Moraes Bezerra (https://orcid.org/0000-0001-5333-2875) ${ }^{1}$ \\ Marcio Galvão Oliveira (https://orcid.org/0000-0001-5281-7889) ${ }^{1}$
}

${ }^{1}$ Instituto Multidisciplinar em Saúde, Universidade Federal da Bahia, campus Anísio Teixeira. Rua Hormindo Barros 58, Candeias. 45029-094 Vitória da Conquista BA Brasil.

jehhmoreno@gmail.com

2 Universidade Estadual do

Sudoeste da Bahia. Vitória

da Conquista BA Brasil.
Abstract Blood pressure measurements taken in a clinical setting are subject to errors, therefore there are advantages to monitoring blood pressure at home, especially in in patients diagnosed with hypertension. The study describes the feasibility of home monitoring to assess blood pressure in primary care and compares blood pressure measured at home and during a medical consultation. This cross-sectional study was carried out with patients whose used home blood pressure in the morning and evening, thrice for seven consecutive day sat home. Participants included patients older than 18 years with suspected whitecoat hypertension, taking antihypertensives, or those intolerant of ambulatory blood pressure monitoring, and excluded patients who did not follow the protocol, suffered from an irregular heart rate, and pregnant women. Of the 134 patients who participated in the study, 63.3\% had altered blood pressure when measured at health facilities and $48 \%$ had higher blood pressure at home. The mean difference between the methods was $10.1 \mathrm{mmHg}$ for systolic and $4.3 \mathrm{mmHg}$ for diastolic. The prevalence of whitecoat hypertension was 19.4\%. Blood pressure monitoring at home is a practicable strategy in the Brazilian healthcare system.

Key words Home blood pressure monitoring, Blood pressure, Hypertension
Resumo A medição da pressão arterial no consultório está sujeita a erros; assim, a monitorização residencial da pressão arterial é utilizada para o monitoramento e diagnóstico da hipertensão. Descrever a viabilidade da monitorização residencial para avaliar a pressão arterial na atenção primária e comparar os valores da pressão arterial através da monitorização residencial e medida de consultório. Estudo transversal realizado com pacientes que utilizaram a monitorização residencial pela manhã e pela noite, em triplicata por sete dias consecutivos em domicílio. Foram incluidos pacientes maiores de 18 anos, com suspeita de hipertensão do avental branco, utilizando anti-hipertensivos ou intolerantes a monitorização ambulatorial. Foram excluídos pacientes que não seguiram o protocolo, aqueles que apresentavam ritmo cardíaco irregular ou mulheres grávidas. 134 pacientes participaram do estudo, 63,3\% apresentaram pressão arterial alteradas em consultório e $48 \%$ pela monitorização residencial. A diferença média dos métodos foi de 10,1 $\mathrm{mmHg}$ para sistólica e 4,3 $\mathrm{mmHg}$ para diastólica. A prevalência de hipertensão do avental branco foi 19,4\%. A monitorização residencial da pressão arterial no sistema de saúde brasileiro provou ser uma estratégia viável.

Palavras-chave Monitorização ambulatorial da pressão arterial, Pressão arterial, Hipertensão 


\section{Introduction}

Blood pressure (BP) measurement is the basis for the diagnosis, treatment, and management of systemic arterial hypertension and all decisions related to this pathology will be influenced by the accuracy of BP measurement ${ }^{1}$. Several factors including environmental conditions, emotional state, methodology, presence of comorbidities such as diabetes, and the device used are directly associated with variations in BP measurement that should be controlled to minimise errors ${ }^{1,2}$. Multiple automated measurements without the presence of a physician or nurse correlate more strongly with accurate BP measurements, compared to those obtained within a health facility ${ }^{3-5}$. Especially in primary care, the simple office measurement is subject to several factors that can lead to errors and a reduced number of readings may show poor reproducibility in the long term, and, consequently, lead to unnecessary treatment $t^{6-8}$.

Ambulatory blood pressure monitoring (ABPM) is the gold standard for the diagnosis of hypertension; however, it has low availability in Brazilian primary care services. It requires doctors with specialist knowledge and is at a high cost for public health services?. Parallel to this, home blood pressure monitoring (HBPM) is a strategy that is used in several countries for the monitoring of hypertension, in order to improve therapeutic adherence, awareness of the disease in the hypertensive patient and diagnosis of hypertension and its variations ${ }^{10}$. HBPM differs from the self-measurement of BP because is accompanied by protocols to carry out the measurements ${ }^{11}$, and is similar to ABPM for the diagnosis and monitoring of patients with hypertension, white coat hypertension (WCH) and Masked Hypertension ${ }^{12}$. Also, the request and interpretation of the result can be performed by any qualified professional in the health care team, which facilitates assessment in underserved areas. Compared to measurements taken in a clinical setting, HBPM improved BP control during treatment, patients had no stress reaction to BP, it increased the possibility of digital storage and telemonitoring, and it was better at predicting clinical outcomes because patients could take BP measurements repeatedly over several days, which allowed for greater reliability in the results ${ }^{2,10}$.

In Brazil, HBPM is not a procedure included in the public health system. It is assumed that the use of HBPM can improve the management and diagnosis of hypertension according to accepted procedures recommended by clinical guidelines.
This study aimed to describe the feasibility of home monitoring to assess blood pressure in primary care and compared differences between blood pressure values measured at home and in a clinical setting.

\section{Methods}

This cross-sectional study was carried out in 15 public basic health units (BHU) in the urban area of the city of Vitória da Conquista (BA), Brazil. This area is part of the HealthRise project that encompasses multidisciplinary actions at three levels of healthcare, focusing on screening and improving care in hypertension and diabetes $^{13}$.The inclusion criteria were all patients older than 18 years of age who were either:(1) awaiting diagnostic confirmation of hypertension with suspected WCH; (2) receiving antihypertensive treatment with difficult-to-control hypertension; or (3) were intolerant to ABPM.

Patients were excluded from the study if they: 1) performed less than 10 measurements; 2) had an arm circumference not supported by the HBPM device (less than $22 \mathrm{~cm}$, or more than 32 $\mathrm{cm})$; 3) suffered from atrial fibrillation or cardiac arrhythmia (identified by the first measurement performed in the office); 4) are pregnant women or had conditions that hampered the use of HBPM; for example, older adults with low levels of literacy who had no responsible person at home to assist with BP measurement.

Data were collected between August 2018 and February 2019. All patients who were eligible in that period and were invited to participate were included. It device used for performing HBPM was an automatic blood pressure monitor (MAM BP 3AC1-1 PC, Microlife), validated according to the British Hypertension Society (BHS) protocol $^{14}$. The monitor performs three automatic measurements without removing or repositioningthe cuff and calculates the mean BP values. It also contains a memory that allows verification of the results by transferring the values to a database. To measure BP in health facilities an automatic device (Omron ${ }^{\circledR}$ HEM-7113) was employed. The measurements were carried out in a doctor's and/or nurse's office, or atout-of-office patient meetings promoted by the healthcare team.

Study participants were chosen during individual visits by doctors/nurses or out-of-office patient meetings. All BP measurements and clinical conducts were recorded in electronic medical 
records. Patients who met the inclusion criteria were invited to be subjected to HBPM.

All health professionals were trained for indications, instructions for operating the devices, guidelines for patients, completing the form, and using software for reading the BP values to minimize errors. This software allowed the transfer of data from the BP monitor including: BP measurements, the number of measurements performed, the times of each measurement, and of the calculated BP average.

A form with questions on identification data, age, use and description of medications used, BP measured at the time of BHU visit was administered to each eligible patient and previous diagnoses (e.g., diabetes or hypertension). Patients with diabetes were registered on the form as diabetic based on medical records, use of hypoglycemic agents, or self-reports. Hypertension patients were those previously diagnosed by the health unit's physician with two or more high BP values (SBP $\geq 140 \mathrm{mmHg}$ and / or DBP $\geq 90 \mathrm{mmHg}$ ), on at least two occasions or HBPM abnormalities ( $\geq 135 / 85 \mathrm{mmHg}$ ). WCH were those with a diagnosis of hypertension, abnormal office measurement values $(\geq 140 / 90 \mathrm{mmHg})$ and normal values by HBPM $(\leq 135 / 85 \mathrm{mmHg})$. Only variables with less than $20 \%$ of values missing were included for analysis ${ }^{15}$. Other variables of interest were the number of BP measurements, mean systolic BP (SBP), and mean diastolic BP (DBP) values throughout the day (morning and evening).

The healthcare professionals completed this form and provided instructions on how to use and care for the device and maintain antihypertensive treatment. Patients took the HBPM device home and were instructed to perform three measurements in the morning and three measurements in the evening for seven days, totalling 42 readings and $14 \mathrm{BP}$ means. All patients performed a test measurement upon receipt of the device to check for possible issues; this measurement was excluded at the time of issuing the results. As a strategy to prevent errors from occurring, verbal instructions were given during the allocation of the devices, along with written instructions and home visits on the days of use. Patients were instructed to perform HBPM in a quiet place, seated with their backs and arms supported and with at least five minutes of rest. After seven days of use the data were transferred and the report was issued by the software.

Any change in the mean $\mathrm{BP}$ would require the scheduling of a medical visit for a physical examination, diagnostic tests, and monitor- ing depending on the comorbidity presented. In addition, all patients with an HBPM mean $\geq$ $135 \times 85 \mathrm{mmHg}$ were advised to make changes to their dietary habits, physical activity, or current therapy.

Data were analysed using SPSS Statistic 23 software. The Kolmogorov-Smirnov test was used to evaluate normality of the data. The paired T-Test was used to assess office BP measurements versus HBPM. Continuous variables with normal distribution were shown as means and standard deviations. The odds ratio was calculated to evaluate the variables associated with uncontrolled BP in the office and by HBPM. Values of $p<0.05$ were considered significant. Bland-Altman plots were generated by MedCalc (version 18.11.3) to visualize agreement between SBP/DBP in the office and HBPM.

This study was approved by the Research Ethics Committee of the Multidisciplinary Health Institute, Federal University of Bahia.

\section{Results}

A total of 142 patients evidenced HBPM indication criteria, of which eight were excluded because they did not provide a sufficient number of BP measurements by HBPM. The population evaluated consisted of 134 patients (Table 1).

The majority of participants were hypertensive, referred for antihypertensive therapy, and $73.8 \%$ of the requests for HBPM were intended for the monitoring of drug treatment.

The number of patients with elevated BP was higher than HBPM, as well as the mean values for SBP and DBP, as measured by health professionals. The mean SBP difference was $10.1 \mathrm{mmHg}$, and DBP was $4.3 \mathrm{mmHg}(\mathrm{p}<0.05)$ (Table 2).

In the 134 patients, the prevalence of $\mathrm{WCH}$ was $19.4 \%$. In patients with diabetes mellitus, this prevalence was $26.2 \%$.

In all variables analysed, office BP was higher than the HBPM. Only ages $\leq 60$ years showed a lower odds ratio (0.2) of high HBPM. The odds of obtaining an alternative HBPM result in patients with hypertension and diabetes was $2.7 \%$ (Table 3).

The Bland-Altman plots showed low agreement between measurements of office and HBPM (Figure 1). The mean differences drawn in the central lines were far from zero with values of $10 \mathrm{mmHg}$ for SBP, and $4.4 \mathrm{mmHg}$ for DBP, $(p<0.01)$. 


\section{Discussion}

In this study we used HBPM to evaluate hypertension in primary care patients. Office BP was altered in $62.3 \%$ of the cases, while $48 \%$ of cases showed an alteration in home BP.

This difference may be related to factors such as environment, emotional state, and presence of

Table 1. Characteristics of 134 participants, Home Blood Pressure Monitoring indications and results.

\begin{tabular}{|c|c|c|}
\hline Features & $\mathbf{N}$ & $\%$ \\
\hline Age (mean) & 56.9 & \\
\hline \multicolumn{3}{|l|}{ Gender } \\
\hline Female & 93 & 69.4 \\
\hline Male & 41 & 30.6 \\
\hline \multicolumn{3}{|l|}{ Hypertensive* } \\
\hline Yes & 100 & 76.9 \\
\hline No & 18 & 13.8 \\
\hline Do not know & 12 & 9.2 \\
\hline \multicolumn{3}{|l|}{ Diabetes $^{*}$} \\
\hline Yes & 33 & 25.4 \\
\hline No & 97 & 74.6 \\
\hline \multicolumn{3}{|l|}{ Use of medicines ${ }^{\star}$} \\
\hline Yes & 114 & 87.7 \\
\hline No & 16 & 12.3 \\
\hline \multicolumn{3}{|l|}{ HBPM indications } \\
\hline $\begin{array}{l}\text { Monitoring of antihypertensive } \\
\text { therapy }\end{array}$ & 96 & 73.8 \\
\hline White coat hypertension diagnosis & 10 & 7.7 \\
\hline Hypertension diagnosis & 24 & 18.5 \\
\hline \multicolumn{3}{|l|}{ Office and HBPM results } \\
\hline \multicolumn{3}{|l|}{ Office Measurement $\geq 140 \times 90 \mathrm{mmHg}$} \\
\hline Yes & 82 & 61.2 \\
\hline No & 52 & 38.8 \\
\hline \multicolumn{3}{|l|}{$\mathrm{HBPM} \geq 135 \times 85 \mathrm{mmHg}$} \\
\hline Yes & 65 & 48.5 \\
\hline No & 69 & 51.5 \\
\hline \multicolumn{3}{|l|}{ White coat hypertension } \\
\hline Yes & 26 & 19.4 \\
\hline No & 108 & 80.6 \\
\hline
\end{tabular}

observers during office BP measurements, and can be minimized when several measures of BP are performed by the patient at home $\mathrm{e}^{3,16,17}$. Our study shows similar results to those of existing studies, in which HBPM provides more accurate values when compared to in-house assessment by health professionals $s^{2,18,19}$.

The most common indication for using HBPM was to monitor drug therapy $(73.8 \%)$. This is because it is possible to improve adherence to drug therapy, adjust dosage, and identify whether therapy is effective or causing adverse effects ${ }^{4,20}$.

The HBPM device is easy to use, requires only a few minutes per day to perform measurements, records measurements automatically, does not cause discomfort, and is well accepted, including in older adults ${ }^{11,21}$. However, it is crucial that HBPM is prescribed with caution in patients with physical and cognitive restrictions ${ }^{22}$, as improper handling of the device or inaccurate clamp placement may interfere with the quality of the measurement. In these cases, measurements performed by a trained family member is an effective alternative ${ }^{22}$.

BP measured in the office was slightly higher, with mean differences of $10.1 \mathrm{mmHg}$ and $4.3 \mathrm{mmHg}$ for SBP and DBP, respectively; this corroborates the notion that SBP can vary up to $30 \mathrm{mmHg}$ when emotional factors are involved ${ }^{23}$. It is suggested that the office measurement tends to be high due toWCH. Furthermore, office BP measurement may be an unreliable technique for the diagnosis and monitoring of hypertension. This is because it is based only ona small number of measurements and can be influenced by environmental conditions ${ }^{18}$. Some studies have shown that the diagnosis of hypertension, based on only two measurements performed on separate occasions, may lead to an increase in false-positive results ${ }^{24}$.

Due to the variability of $\mathrm{BP}$, a concordance analysis was performed using the Bland-Altman plots, which best represent the difference between the two methods. Low agreement between HBPM and office BP was observed through the

Table 2. Office blood pressure versus Home Blood Pressure Monitoring measurements.

\begin{tabular}{lrrcrc}
\hline & BP office & HBPM & Mean difference & 95\% CI & p-value $^{\star}$ \\
\hline SBP & $147 \pm 21.3$ & $136 \pm 16.2$ & $10.1 \pm 17$ & $7.1-13.1$ & $<0.05$ \\
DBP & $87 \pm 15.5$ & $82 \pm 10.6$ & $4.3 \pm 12$ & $2.2-6.4$ & $<0.05$ \\
\hline
\end{tabular}


Table 3. Patients variables associated with uncontrolled office blood pressure and by Home Blood Pressure Monitoring, Bahia Brazil 2018-2019.

\begin{tabular}{lcccccccc}
\hline & $\begin{array}{c}\text { High BP office } \\
(\mathbf{\%})\end{array}$ & OR & $\mathbf{p}^{*}$ & $\mathbf{C I}$ & $\begin{array}{c}\text { Changed } \\
\text { HBPM (\%) }\end{array}$ & OR & $\mathbf{p}^{*}$ & CI \\
\hline N patients & $82(63.3 \%)$ & - & - & - & $65(48 \%)$ & - & - & - \\
Variable & & & & & & & & \\
Age, $\leq 60$ years & $42(51 \%)$ & 0.4 & 0.01 & $0.1-0.8$ & $26(40 \%)$ & 0.2 & 0.01 & $0.1-0.4$ \\
Female, gender & $54(65 \%)$ & 0.5 & 0.20 & $0.2-1.3$ & $47(72 \%)$ & 1.3 & 0.40 & $0.6-2.7$ \\
Hypertension & $67(81 \%)$ & 2.0 & 0.07 & $0.9-4.8$ & $56(86 \%)$ & 2.7 & 0.02 & $1.1-6.5$ \\
Diabetes & $24(29 \%)$ & 1.9 & 0.10 & $0.8-4.8$ & $22(34 \%)$ & 2.7 & 0.01 & $1.1-6.2$ \\
Use of medicines & $76(92 \%)$ & 3.5 & 0.01 & $1.1-10.4$ & $59(93 \%)$ & 3.2 & 0.04 & $0.98-10$ \\
\hline
\end{tabular}

BP office: office blood pressure; HBPM: Home blood pressure monitoring. ${ }^{\star}$ chi-square test.

Source: Author's elaboration.
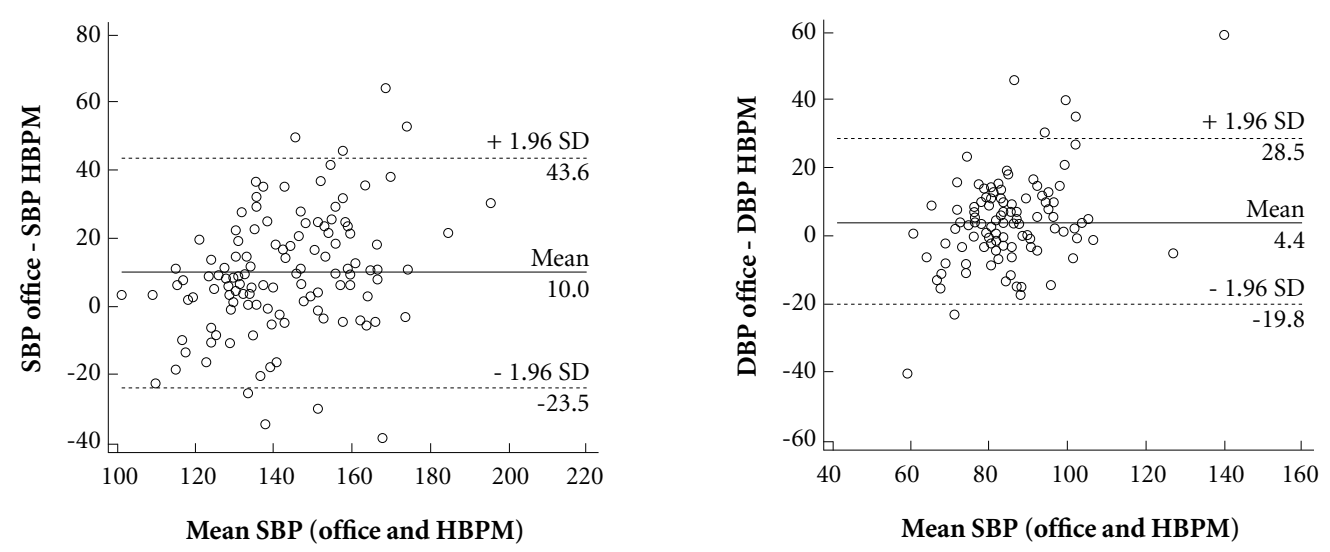

Figure 1. Analysis of bland-altman agreement between systolic and diastolic blood pressure $(\mathrm{mmHg})$ values determined by home blood pressure monitoring and office blood pressure.

Source: Author's elaboration.

variations in mean BP between these two methods. This confirmed that the office measure overestimated BP values in these individuals.

In our patients, the rate of $\mathrm{WCH}$ was $19.4 \%$, and although similar to other studies, this rate varies depending on the characteristics of the patients included ${ }^{8}$. A meta-analysis performed with a total of 14 studies showed that WCH is associated with an increased risk of cardiovascular disease and all-cause mortality in people who, initially, had not undergone antihypertensive treatment ${ }^{25}$. This is likely due to the linear association between BP levels and cardiovascular risk ${ }^{26,27}$. HBPM allows a precise diagnosis of $\mathrm{WCH}^{11}$, reduces the number of visits to the doctor's office, prevents the inappropriate prescription of medication, and prevents effects associated with antihypertensive treatment, especially in older patients or those with multiple comorbidities ${ }^{7}$.

Patients with diabetes mellitus accounted for $26.2 \%$ of those diagnosed with WCH which can be partially explained by arterial stiffness found in this patient cohort ${ }^{2}$. Indeed, HBPM has been studied in diabetic patients and it has been noted to be similar or superior to BP measured in clinical settings in predicting outcomes ${ }^{2,4}$. In addition, HBPM can be a strong independent predictor of impaired renal function in diabetics ${ }^{2}$. Therefore, the use of HBPM in diabetic patients is recommended as it is a tool capable of identifying variations in measurements, especially in lower blood pressure values.

A patient's non-compliance with home and follow-up measurements outlined in the mon- 
itoring protocolmay influence the outcome of HBPM $^{16}$. The number of days required to carry out the measurements remains controversial ${ }^{28}$, and in our study, we preferredthe seven-dayperiod because it was a reliable approach.

HBPM is a new technology in Brazil, but it has been used for decades in developed countries ${ }^{17}$. Concerning feasibility, HBPM is not always available and rarely used in Brazil, as the training and qualifications required to perform this technique are not provided within the Brazilian health care system. Despite this, the HBPM was found to be a very effective strategy for $\mathrm{WCH}$ diagnosis, and analysis showed that HBPM requires less financial and practical investments when compared to $\mathrm{ABPM}^{29}$. An inter-domain evaluation of primary care providers has shown that the most critical barriers to conducting $\mathrm{ABPM}$ are related to costs, infrastructure, and inaccessibility of ABPM testing centres. Regarding HBPM, the primary concerns are related to patients' failure to comply with the test protocol, lack of skills, or insufficient knowledge for performing the measurements ${ }^{18}$.

A study evaluating knowledge about ABPM and HBPM showed that only $60 \%$ of ABPM examinations are requested and that most physicians report having no technical knowledge for ABPM interpretation ${ }^{12}$. Another study with 756 physicians and 146 hypertensive patients revealed that $13 \%$ of professionals preferred BP self-monitoring compared to office measurement ${ }^{9}$. Unlike
ABPM, HBPM is more widely accepted by patients, although it requires the patient to be committed incarrying out measurements, which can be a challenge for this monitoring strategy $y^{28}$.

Our study has some limitations. Firstly, office BP measures were performed only on one occasionfor each patient, which may have overestimated the SBP and DBP values used as a reference for comparison with HBPM. Secondly, the number of measurements was not equitable in all healthcare professionals trained to perform HBPM. Thirdly, the turnover of professional staff within the service and the training needs of new staff may have influenced the population's access to HBPM. As we didn't follow the patients, we couldn't to understand change in prescribing or other behavior of clinicians in response to this data as part of the feasibility assessment.

\section{Conclusion}

The use of HBPM in the Brazilian healthcare system was a practicable strategy. It is superior to the office setting in confirming the diagnosis of $\mathrm{WCH}$, as well as monitoring and diagnosing hypertension. This HBPM technology is more accessible than ABPM, better accepted by patients, and more reliable than office BP. Thus, strategies to implement HBPM for diagnosing and monitoring hypertension should be established in primary care. 


\section{Collaborations}

We declare that all authors of this article participated directly in the planning, execution, reading and approval of this final version.

\section{Acknowledgment}

This research is part of HealthRise, in partnership with the Medtronic Foundation, Abt Associates, and the Institute for Health Metrics and Evaluations. We are grateful to all health professionals and patients involved in the study. We would also like to thank the staff at Medlevensohn ${ }^{\circledR} \mathrm{Com}$ pany who provided the HBPM software and the developers of the Medbem ${ }^{\circledR}$ system.

\section{References}

1. O’Brien E, Asmar R, Beilin L, Imai Y, Mallion J, Mancia G, Mengden T, Myers M, Padfield P, Palatini P, Parati G, Pickering T, Redon T, Staessen J, Stergiou G. Verdecchia P. European Society of Hypertension recommendations for conventional, ambulatory, and home blood pressure measurement. $J$ hypertension 2003; 21(5):821-848.

2. Kim SG. Clinical implications of ambulatory and home blood pressure monitoring. Korean Circulation J 2010; 40(9):423-431.

3. Filipovsky J, Seidlerova J, Kratochvil Z,Hronova M, Mayer O. Automated compared to manual office blood pressure and to home blood pressure in hypertensive patients. Blood Pressure 2016; 25(4):228-234.

4. Parati G, Stergiou GS, Asmar R, Bilo G, de Leeuw P, Imai Y, Kario K, Lurbe E, Manolis A, Mengden T, O'Brien E, Ohkubo T, Padfield P, Palatini P, Pickering T, Redon J, Revera M, Ruilope LM, Shennan A, Staessen JA, Tisler A, Waeber B, Zanchetti A, Mancia G. European Society of Hypertension guidelines for blood pressure monitoring at home: a summary report of the Second International Consensus Conference on Home Blood Pressure Monitoring. J hypertension 2008; 26(8):1505-1526.

5. Ishikawa J, Nasothimiou EG, Karpettas N, McDoniel S, Feltheimer SD, Stergiou GS, Pickering TG, Schwartz JE. Automatic office blood pressure measured without doctors or nurses present. Blood Pressure Monitoring 2012; 17(3):96-102.

6. Alessi A, Brandão AA, Pierin Â, Feitosa, Magalhães A, Machado C, Forjaz C, Atie C, Giorgi D, Mion D, Rosa E, Nobre F, Silva G, Chaves H, Pascoal I, Guimarães, J, Santello J, Ribeiro J, Praxedes J, Ortega K, Costa L, Bortolotto L, Gomes M, Wajngarten M, Gus M, Kohlmann O, Veiga P, Geleilete J. IV Diretriz para uso da monitorização ambulatorial da pressão arterial; II Diretriz para uso da monitorização residencial da pressão arterial. Arquivos Brasileiros de Cardiologia 2005; 85:1-18.

7. Lovibond K, Jowett S, Barton P, Caulfield M, Heneghan C, Hobbs FD, Hodgkinson J, Mant J, Martin U, Williams B, Wonderling D, McManus RJ. Cost-effectiveness of options for the diagnosis of high blood pressure in primary care: a modelling study. Lancet 2011; 378(9798):1219-1230.

8. Alves LMM, Nogueira MS, Godoy Sd, Hayashida M, Cárnio EC. Prevalência de Hipertensão do Avental Branco na Atenção Primária de Saúde. Arquivos Brasileiros de Cardiologia 2007; 89:28-35.

9. Logan AG, Dunai A, McIsaac WJ, Irvine MJ, Tisler A. Attitudes of primary care physicians and their patients about home blood pressure monitoring in Ontario. J hypertension 2008; 26(3):446-452.

10. Muhammad J, Jamial MM, Ishak A. Home blood pressure monitoring has similar effects on office blood pressure and medication compliance as usual care. Korean J Fam Med 2019; 40(5):335-343. 
11. Nobre F, Mion Júnior D, Gomes MAM, Barbosa ECD, Rodrigues CIS, Neves MFT, Brandão AA, Alessi AA, Feitosa AM, Machado CA, Poli-de-Figueiredo CE, Amodeo C, Forjaz CLM, Giorgi DMA, Coelho EB, Lima Júnior E, Plavnik FL, Silva GV, Chaves Jr. H, Vilela-Martin JFV, Ribeiro JM, Gusmão JL, YugarToledo JC, Bortolotto LA, Scala LCN, Malachias MVB, Wajngarten M, Gus M, Passarelli Júnior. O, Jardim PCBV, Miranda RD, Paula RB, Ferreira-Filho SR, Andrade S, Geleilete TJM, Koch VHK, Souza WKSB, Oigman W, Póvoa RMS. 6a Diretrizes para uso da monitorização ambulatorial da pressão arterial e 4a Diretriz para uso da monitorização residencial da pressão arterial. Arq Bras Cardiol 2018; 110(5 Supl.1):1-29.

12. Chia YC, Buranakitjaroen $\mathrm{P}$, Chen $\mathrm{CH}$, Divinagracia $\mathrm{R}$, Hoshide S. Current status of home blood pressure monitoring in Asia: Statement from the HOPE Asia Network. 2017; 19(11):1192-1201.

13. What is HealthRise? HealthRise, 2019. [cited 2019 Mar 15]. Available from: https://www.health-rise. org/; 2019

14. Topouchian JA, El Assaad MA, Orobinskaia LV, El Feghali RN, Asmar RG. Validation of two devices for self-measurement of brachial blood pressure according to the International Protocol of the European Society of Hypertension: the SEINEX SE-9400 and the Microlife BP 3AC1-1. Blood Pressure Monitoring 2005; 10(6):325-331.

15. Malachias MVB, Gomes MAM, Nobre F, Alessi A, Feitosa AD, Coelho EB. 7a Diretriz Brasileira de Hipertensão Arterial: Capítulo 2 - Diagnóstico e Classificação. Arq Bras Cardiol 2016; 107(Supl. 3): 7-13.

16. Andreadis EA, Angelopoulos ET, Tsakanikas AP, Agaliotis GD, Kravvariti SD, Mousoulis GP. Automated office versus home measurement of blood pressure in the assessment of morning hypertension. Blood Pressure Monitoring 2012; 17(1):24-34.

17. Póvoa TIR, Jardim TV, Carneiro CS, Ferreira V, Mendonça K, Morais P, Nascente F, Souza W, Sousa A, Jardim P. Monitorização Residencial da Pressão Arterial (MRPA) como alternativa para confirmação diagnóstica de Hipertensão Arterial em adolescentes de uma capital brasileira com pressão de consultório elevada. Arquivos Brasileiros de Cardiologia 2017; 109(3):241247.

18. Eguchi K, Kuruvilla S, Ishikawa J, Ogedegbe G, Gerin W, Schwartz JE, Pickering TG. Correlations between different measures of clinic, home, and ambulatory blood pressure in hypertensive patients. Blood Pressure Monitoring 2011; 16(3):142-148.

19. Kronish IM, Kent S, Moise N, Safford M, Kynerd R, O’Beirne R, Sullivan A, Muntner P2.. Barriers to conducting ambulatory and home blood pressure monitoring during hypertension screening in the United States. J Am Soc Hypertension 2017; 11(9):573-580.

20. Visanuyothin S, Plianbangchang S, Somrongthong R. An integrated program with home blood-pressure monitoring and village health volunteers for treating poorly controlled hypertension at the primary care level in an urban community of Thailand. Integrated Blood Pressure Control 2018; 11:25-35.
21. Alpérovitch A, Cacciolati C, Dufouil C, Tzourio C, Hanon O. Feasibility of Home Blood Pressure Measurement in Elderly Individuals: Cross-Sectional Analysis of a Population-Based Sample. Am J Hypertension 2012; 25(12):1279-1285.

22. Plichart M, Seux ML, Caillard L, Chaussade E, Vidal JS, Boully C, Hanon O.. Home blood pressure measurement in elderly patients with cognitive impairment: comparison of agreement between relative-measured blood pressure and automated blood pressure measurement. Blood Pressure Monitoring 2013; 18(4):208214.

23. Mancia G, Bertinieri G, Grassi G, Parati G, Pomidossi G, Ferrari A, Gregorini L, ZanchettiA..Effects of blood-pressure measurement by the doctor on patient's blood pressure and heart rate. Lancet 1983; 2(8352):695-698.

24. Niiranen TJ, Asayama K, Thijs L, Johansson JK, Hara A, Hozawa A, Tsuji I, Ohkubo T, Jula A, Imai Y, Staessen J. Optimal number of days for home blood pressure measurement. Am J hypertension 2015; 28(5): 595-603.

25. Huang $Y$, Huang W, Mai W, Cai X, An D, Liu Z, Huang $\mathrm{H}$, Zeng J, Hu Y, Xu D.. White-coat hypertension is a risk factor for cardiovascular diseases and total mortality. J Hypertension 2017; 35(4):677-688.

26. Mancia G, Bombelli M, Seravalle G, Grassi G. Diagnosis and management of patients with white-coat and masked hypertension. Nature Rev Cardiology 2011; 8(12):686-693.

27. Kollias A, Ntineri A, Stergiou GS. Is white-coat hypertension a harbinger of increased risk? Hypertens Res 2014; 37(9):791-795.

28. Shimbo D, Abdalla M, Falzon L, Townsend RR, Muntner P. Role of Ambulatory and Home Blood Pressure Monitoring in Clinical Practice: A Narrative Review. Annals Internal Med 2015; 163(9):691-700.

29. Krakoff LR. Cost-effectiveness of ambulatory blood pressure: a reanalysis. Hypertension 2006; 47(1):29-34.

Article submitted 09/03/2020

Approved 08/06/2020

Final version submitted 10/06/2020

Chief editors: Romeu Gomes, Antônio Augusto Moura da Silva 